\title{
Estudo sobre as variabilidades e as tendências climáticas interanuais na região norte do Brasil
}

\section{Study on the interannual variabilities and climate trends in the northern region of Brazil}

\author{
Júlio César Penereiro ${ }^{1}$ \\ Denise Helena Lombardo Ferreira $\left.{ }^{2}{ }^{*}\right)$ \\ Monica Cristina Meschiatti ${ }^{3}$
}

\section{Resumo}

O objetivo deste trabalho foi avaliar presenças de tendências em séries temporais, relativas aos índices anuais das precipitações pluviométricas e de temperaturas mínima, média e máxima, registradas em quarenta localidades pertencentes à região norte do Brasil. Foram utilizadas as medições climáticas realizadas pelo Instituto Nacional de Meteorologia no período de 1961 a 2015. Para identificar a presença de tendência em cada série temporal foram aplicadas análises de regressão linear e os testes não paramétricos de Mann-Kendall e de Pettitt, considerando os níveis de significância comumente adotados na literatura científica (5\% e 10\%). Os resultados indicam que a maioria das cidades avaliadas $(75,0 \%)$ não registraram tendências na precipitação, enquanto que, para as temperaturas, a maioria acusou tendência positiva para a temperatura média $(57,5 \%)$, seguido das temperaturas máxima e da mínima (50,0 \% cada). Não houve registro de tendência de diminuição das temperaturas média e máxima nas localidades trabalhadas. Mapas das distribuições de tendências indicam que a maior parte das ocorrências nas temperaturas se localiza ao longo dos rios Solimões, Amazonas e Tocantins.

Palavras-chave: Séries temporais, análises estatísticas, mudanças climáticas, região amazônica.

\section{Abstract}

The objective of this work was to evaluate the possible presence of trends in annual indices of time-series regarding rainfall, minimum, average and maximum temperature registered in forty localities that belong to the northern region of Brazil. The climatic measurements used were produced by the National Institute of Meteorology during

1 Dr.; Astronomia; Universidade de São Paulo, USP, Brasil; Docente e Pesquisador na Pontifícia Universidade Católica de Campinas, PUC Campinas, Brasil; Endereço: Rua Professor Dr. Euryclides de Jesus Zerbini, 1516 - Parque Rural Fazenda Santa Cândida, Campinas - SP, 13087-571; E-mail: jcpenereiro@yahoo.com.br

2 Dra.; Matemática; Universidade Estadual Paulista Júlio de Mesquita Filho, UNESP, Brasil; Professora pesquisadora da Pontifícia Universidade Católica de Campinas e do Programa de Pós-Graduação interdisciplinar stricto sensu em Sustentabilidade desta Universidade, atuando na linha de pesquisa de Planejamento, Gestão e Indicadores de Sustentabilidade; Pontifícia Universidade Católica de Campinas, Instituto de Informática; Endereço: Rodovia D. Pedro I, Km. 136 Parque das Universidades, 13086900 - Campinas, SP - Brasil; E-mail; lombardo@puc-campinas.edu.br (*) Autor para correspondências

3 Mestranda; Agricultura Tropical e Sub Tropical; Instituto Agronômico de Campinas, IAC, Brasil; Instituto Agronômico de Campinas, Centro de Pesquisa e Desenvolvimento de Ecofisiologia e Biofísica; Endereço: Avenida Theodureto de Almeida Camargo, 1500, Guanabara, 13012902 - Campinas, SP - Brasil; E-mail: monicameschiatti@hotmail.com

\begin{tabular}{llllll}
\hline Ambiência & Guarapuava (PR) & v.14n.1 & p.119-139 & Jan/Abr 2018 & ISSN $1808-0251$
\end{tabular}


the period of 1961 to 2015. To identify the presence of trends in each time series, linear regression analyses and nonparametric tests of Mann-Kendall and Pettitt were applied, considering the significance levels usually adopted in scientific literature (5\% and 10\%). The results confirm that the majority of the cities evaluated $(75,0 \%)$ did not record trends in precipitation; while, concerning the temperatures, most have recorded positive trends on average temperature $(57,5 \%)$, followed by the maximum and minimum temperatures $(50,0 \%$ each). There were no decrease records on average and maximum temperatures in any of the localities studied. Maps of trends' distributions indicate that most occurrences on temperatures are located along the rivers Solimões, Amazonas and Tocantins.

Keywords: Time series, statistical analysis, climate changes, amazon region.

\section{Introdução}

Um dos temas de interesse científico-acadêmico da atualidade está relacionado à identificação de evidências observacionais voltadas às variações e mudanças do clima. Estudar as alterações climáticas ocorridas no passado possibilita compreender melhor as variabilidades inferidas no presente, além de subsidiar melhores averiguações no comportamento do clima futuro. Esses estudos são realizados por modelos que levam em consideração diferentes aspectos socioeconômicos, como uso da terra, em especial os efeitos da urbanização histórica e da expansão agropecuária, concentrações de gases de efeito estufa, entre outros (PBMC, 2013).

Apesar de ainda existirem muitas controvérsias e incertezas a respeito da influência humana sobre o clima, variações climáticas desde 1970 têm sido identificadas, sendo possível afirmar que uma parcela dessa variabilidade está relacionada ao atual aquecimento global observado (TRENBERTH et al., 2007; IPCC, 2013). Neste sentido, as evidências de mudanças nos regimes de temperaturas do ar e das precipitações são frequentemente apontadas como causa da interferência do ser humano no ambiente, além da crescente urbanização sem planejamento adequado do uso do solo (KARL et al., 1988; ZHENMEI et al., 2008).

As alterações causadas no uso do solo, além do acelerado desenvolvimento urbano e agroindustrial ocorrido nas últimas décadas, levaram à degradação das florestas e dos recursos hídricos no que tange aos aspectos quantitativos e qualitativos (GROPPO et al., 2001), em particular na região norte do Brasil (ANA-1, 2012). Gradativamente o desmatamento na Amazônia vem substituindo a superfície mais escura da floresta por áreas mais brilhantes, como pastagens, plantações e represas, implicando maior fração de luz solar refletida para o espaço. Como consequência disso, as projeções mais críticas para essa região brasileira indicam que ocorrerá uma "savanização" da parte sudeste da floresta amazônica, como causa das profundas alterações no solo e na vegetação, o que acarretará em significativas perdas nos estoques de carbono. Essas constatações indicam a necessidade de se realizar estudos mais aprofundados sobre as ações originadas nos processos de mudança de uso do solo, em especial incluindo-se os efeitos das evoluções de cidades, da expansão agropecuária e dos desmatamentos em nível nacional, todos em várias escalas temporais (PBMC, 2013).

Em virtude do alto grau de vulnerabilidade da região norte do Brasil, presume-se que as projeções mais preocupantes para o final do século são para os biomas Amazônia e Caatinga, cujas tendências de elevação na temperatura do ar e de diminuição nos padrões regionais de chuva são 
maiores do que a variação média global (MARENGO et al., 2009). Ao apontar uma causa física para isso, sugere-se que essa alteração climática de redução na precipitação esteja associada aos padrões oceânicos tropicais como as anomalias registradas no aquecimento dos oceanos Pacífico e Atlântico, os quais alteram o regime de vento na região norte, induzindo uma diminuição na umidade, prevalecendo uma circulação atmosférica descendente sobre o Brasil tropical, inibindo a formação de nuvens convectivas e, justificando desta forma, as condições de chuva abaixo do normal (TRENBERTH et al., 2007).

Não obstante, a deficiência de uma rede observacional coerentemente espalhada pelo Brasil, além da falta de observações meteorológicas de longo prazo, bem como de interrupções nas medições, são alguns dos fatores limitantes para se estudar o clima com maior precisão. Neste sentido, para realizar estudos confiáveis envolvendo as variáveis climáticas observacionais devese aplicar e analisar métodos estatísticos paramétricos e não paramétricos, pois eles possuem um embasamento matemático mais rigoroso para os modelos teóricos de descrição climática (SANSIGOLO; KAYANO, 2010).

Diante desse cenário de incertezas quanto aos impactos causados pelas eventuais mudanças em séries climáticas, a presente pesquisa visa contribuir com as análises de tendências dos regimes anuais de temperaturas do ar e precipitação empregando os dados meteorológicos da região Norte do Brasil. Realizaram-se análises das variabilidades de cada série temporal e identificaram-se, por meio de testes estatísticos paramétricos e não paramétricos, ocorrências dos locais e a partir de quando iniciou a ocorrência de tendências significativas. Desta forma, foi possível confeccionar e analisar mapas contendo as distribuições espaciais das tendências detectadas, como será descrito ao longo deste artigo.

Desta maneira, julga-se que estudos desta natureza possam também contribuir para uma reflexão a respeito dos impactos ambientais em diversos setores da sociedade, sobretudo aqueles vinculados à agricultura ou ao saneamento e abastecimento básico de água.

\section{Variáveis climáticas do estudo}

Foram utilizadas as séries temporais diárias de temperatura máxima (T-máx.), média (T-méd.) e mínima (T-mín.), além da precipitação pluvial (Prec.) de 40 localidades, distribuídas pelos sete estados da região norte do Brasil, e disponibilizadas no Banco de Dados Meteorológicos para Ensino e Pesquisa (BDMEP) do Instituto Nacional de Meteorologia (INMET), compreendendo o período de 1961 a 2015 (INMET, 2015).

A Figura 1 mostra o mapa da região norte destacando as posições das estações meteorológicas de onde foram extraídos os dados aqui trabalhados. As informações de todas as séries temporais tratadas nessa pesquisa estão resumidas na Tabela 1 , na qual estão destacadas as identificações numéricas (\#), para eventuais análises e comparações com relações às posições nos mapas e tabelas que virão a seguir, além dos nomes das localidades seguido do respectivo código, o qual identifica a estação meteorológica convencional do INMET, suas coordenadas geográficas e o período da série temporal trabalhada. Como o BDMEP divulga dados de temperatura média compensada, no presente trabalho a temperatura média do ar (T-méd.) foi considerada pelo cômputo da média diária entre T-mín. e T-máx. Além disso, na avaliação dos dados para cada tipo de temperatura foi considerada a média anual, enquanto que para precipitação pluviométrica levou-se em consideração o total anual. 


\section{Figura 1 - Localização geográfica das estações medidoras do INMET usadas no presente estudo}

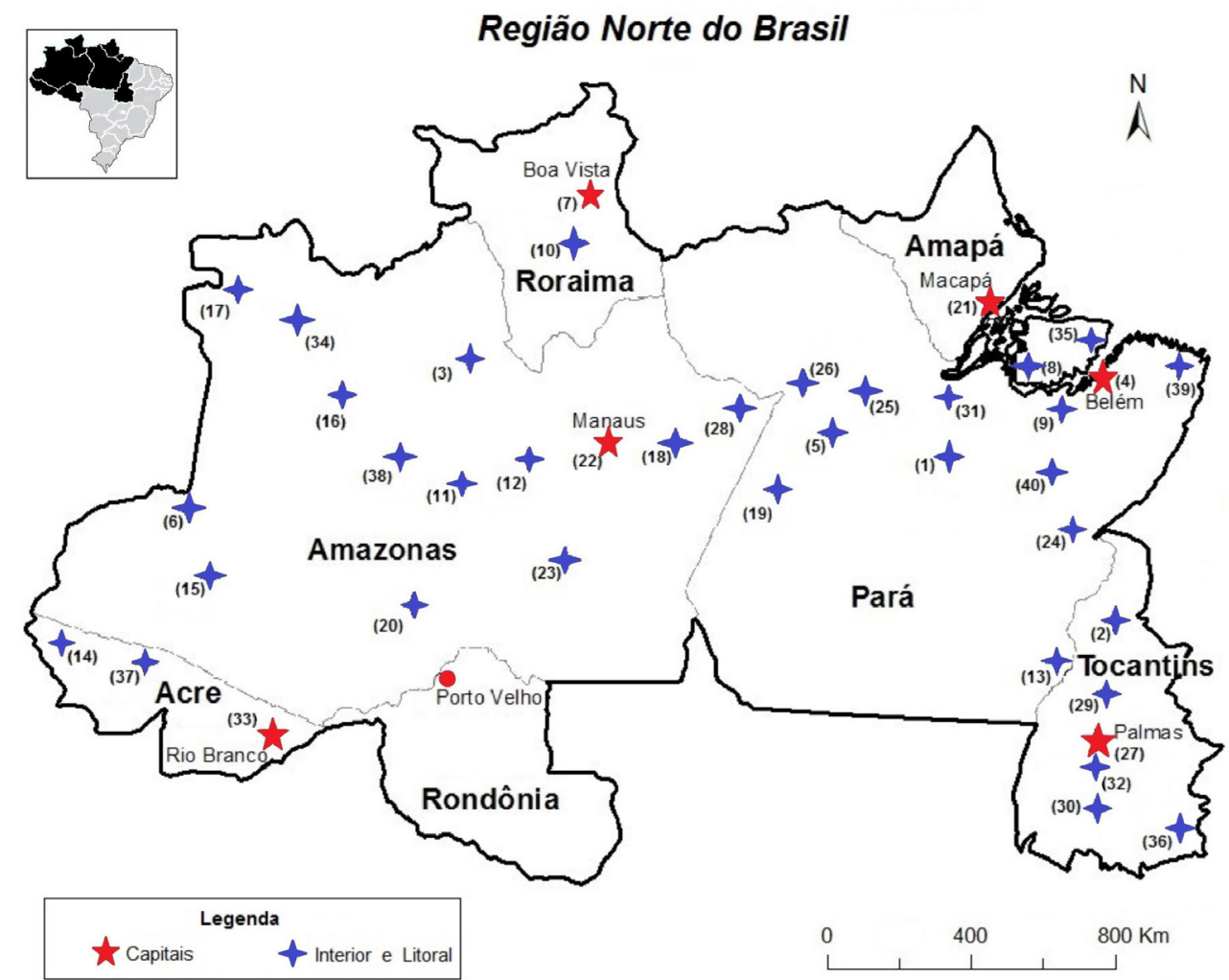

Fonte: Elaborada pelos próprios autores.

O período estudado de cada série depende dos dados disponíveis de uma determinada estação medidora, como é destacado na última coluna da Tabela 1. Ressalta-se que em algumas estações foram identificadas falhas nas séries que, segundo Pickering et al. (1994), podem ter acontecido devido à quebra do equipamento, ausência do responsável pela medição, erros na calibração instrumental, medidas eliminadas devido a equívoco na leitura, além da mudança de localização das estações ou na exposição dos aparelhos.

É importante salientar as questões envolvidas na qualidade dos dados meteorológicos, que pode comprometer seriamente os resultados de muitas pesquisas. Nesse sentido, as medidas tratadas devem ser baseadas em pressupostos corretos e elaborados com metodologia matemática adequada. Vale salientar que são comuns problemas como: descontinuidade espacial e temporal dos dados, má distribuição das estações medidoras, dificuldades em se manter equipamentos em áreas perigosas ou inóspitas, mudança dos equipamentos para locais bem diferentes das condições iniciais, além da falta de verba para a instalação ou manutenção dos equipamentos.

No intuito de minimizar e preencher possíveis falhas nos dados meteorológicos vários métodos podem ser utilizados, como o emprego da média dos dados observados antes ou após a data da falha (normal climatológica), ou ainda o uso de dados sintéticos obtidos pelos chamados geradores de dados (CHIBANA et al., 2005). 
Tabela 1 - Relação das localidades do INMET tratadas neste trabalho

\begin{tabular}{|c|c|c|c|c|c|c|}
\hline & Cidade- Estado & Estação & Lat. $\left({ }^{\circ}\right)$ & Long. $\left({ }^{\circ}\right)$ & Alt. (m) & Série \\
\hline 1 & Altamira- PA & 82353 & $-3,21$ & $-52,21$ & 74,04 & $1961-2015$ \\
\hline 2 & Araguaína- TO & 82659 & $-7,20$ & $-48,20$ & 228,52 & 1984-2015 \\
\hline 3 & Barcelos- AM & 82113 & $-0,96$ & $-62,91$ & 40,00 & $1961-2015$ \\
\hline 4 & Belém- PA & 82191 & $-1,43$ & $-48,43$ & 10,00 & $1961-2015$ \\
\hline 5 & Belterra- PA & 82246 & $-2,63$ & $-54,95$ & 175,74 & $1972-2015$ \\
\hline 6 & Benjamin Constant- AM & 82410 & $-4,38$ & $-70,03$ & 65,00 & $1961-2015$ \\
\hline 7 & Boa Vista- RR & 82024 & 2,81 & $-60,65$ & 90,00 & 1993-2015 \\
\hline 8 & Breves- PA & 82188 & $-1,68$ & $-50,48$ & 14,74 & $1995-2015$ \\
\hline 9 & Cametá- PA & 82263 & $-2,25$ & $-49,50$ & 23,90 & $1970-2015$ \\
\hline 10 & Caracaraí- RR & 82042 & 1,83 & $-61,13$ & 94,05 & $1978-2015$ \\
\hline 11 & Coari- AM & 82425 & $-4,08$ & $-63,13$ & 46,00 & $1970-2015$ \\
\hline 12 & Codajás- AM & 82326 & $-3,83$ & $-62,08$ & 48,00 & $1993-2015$ \\
\hline 13 & Conceição do Araguaia-PA & 82861 & $-8,26$ & $-49,26$ & 156,85 & $1961-2015$ \\
\hline 14 & Cruzeiro do Sul- AC & 82704 & $-7,63$ & $-72,66$ & 170,00 & $1970-2015$ \\
\hline 15 & Eirunepé- AM & 82610 & $-6,66$ & $-69,86$ & 104,00 & 1993-2015 \\
\hline 16 & Fonte Boa- AM & 82212 & $-2,53$ & $-66,16$ & 55,57 & $1990-2015$ \\
\hline 17 & Iauaretê- AM & 82067 & 0,61 & $-69,20$ & 120,00 & $1970-2015$ \\
\hline 18 & Itacoatiara- AM & 82336 & $-3,13$ & $-58,43$ & 40,00 & $1971-2015$ \\
\hline 19 & Itaituba- PA & 82445 & $-4,28$ & $-56,00$ & 45,00 & $1966-2015$ \\
\hline 20 & Lábrea- AM & 82723 & $-7,25$ & $-64,83$ & 61,00 & $1993-2015$ \\
\hline 21 & Macapá- AP & 82098 & $-0,05$ & $-51,11$ & 14,46 & $1968-2015$ \\
\hline 22 & Manaus- AM & 82331 & $-3,11$ & $-59,95$ & 67,00 & $1961-2015$ \\
\hline 23 & Manicoré- AM & 82533 & $-5,81$ & $-61,30$ & 50,00 & $1993-2015$ \\
\hline 24 & Marabá- PA & 82562 & $-5,36$ & $-49,13$ & 95,00 & $1973-2015$ \\
\hline 25 & Monte Alegre- PA & 82181 & $-2,00$ & $-54,08$ & 145,85 & $1975-2015$ \\
\hline 26 & Óbidos- PA & 82178 & $-1,91$ & $-55,51$ & 37,00 & $1970-2015$ \\
\hline 27 & Palmas- TO & 83033 & $-10,19$ & $-48,30$ & 280,00 & 1994-2015 \\
\hline 28 & Parintins- AM & 82240 & $-2,63$ & $-56,73$ & 29,00 & $1993-2015$ \\
\hline 29 & Pedro Afonso- TO & 82863 & $-8,96$ & $-48,18$ & 187,00 & $1977-2015$ \\
\hline 30 & Peixe- TO & 83228 & $-12,01$ & $-48,35$ & 242,49 & $1975-2015$ \\
\hline 31 & Porto de Moz- PA & 82184 & $-1,73$ & $-52,23$ & 15,93 & $1966-2015$ \\
\hline 32 & Porto Nacional- TO & 83064 & $-10,71$ & $-48,41$ & 239,20 & $1961-2015$ \\
\hline 33 & Rio Branco- AC & 82915 & $-9,96$ & $-67,80$ & 160,00 & $1970-2015$ \\
\hline 34 & São Gabriel da Cachoeira- AM & 82106 & $-0,11$ & $-67,00$ & 90,00 & $1961-2015$ \\
\hline 35 & Soure- PA & 82141 & $-0,73$ & $-48,51$ & 10,49 & 1961-2015 \\
\hline 36 & Taguatinga- TO & 83235 & $-12,40$ & $-46,41$ & 603,59 & $1961-2015$ \\
\hline 37 & Tarauacá- AC & 82807 & $-8,16$ & $-70,76$ & 190,00 & 1993-2015 \\
\hline 38 & Tefé- AM & 82317 & $-3,83$ & $-64,70$ & 47,00 & $1970-2015$ \\
\hline 39 & Tracuateuá- PA & 82145 & $-1,06$ & $-46,90$ & 36,00 & $1973-2015$ \\
\hline 40 & Tucuruí- PA & 82361 & $-3,76$ & $-49,66$ & 40,00 & $1971-2015$ \\
\hline
\end{tabular}

Fonte: Elaborada pelos próprios autores.

No presente trabalho optou-se pela utilização do cálculo de interpolação por meio da média com grau três, isto é, calculando a média dos três dias anteriores ou posteriores, se os mesmos também não estivessem com esses erros. Caso as falhas fossem de um período de tempo muito longo, isso é, mais de três dias sem dados, realizou-se uma média entre os três mesmos meses de anos anteriores ou posteriores, conforme cada caso específico. No caso específico da cidade 
paraense de São Félix do Xingu, os dados diários do INMET apresentaram grandes lacunas de informações, portanto decidiu-se por não os considerar no presente levantamento. Ressalta-se ainda que a capital do estado de Rondônia, Porto Velho, não possui estação medidora, portanto não contempla a amostra aqui analisada. Por conta disso, na Figura 1 esta capital está indicada com um círculo vermelho. Ressalta-se que, como informado na legenda da referida figura, as localidades abordadas (interior e litoral) estão representadas em forma de cruz na coloração azul, enquanto que as capitais estão no formato de estrela em coloração vermelha.

De posse dos dados, os mesmos foram organizados e tratados em planilhas do software Microsoft Office Excel, o que possibilitou a realização dos cálculos visando inferir a ocorrência de uma eventual tendência e a variabilidade dos parâmetros climáticos de interesse, além da geração de gráficos e a realização de análises estatísticas acuradas.

\section{Métodos estatísticos aplicados à climatologia}

Após a realização da análise exploratória de uma determinada série temporal, é conveniente verificar se a possível tendência, ou mudança abrupta observada graficamente nessa etapa, seja identificada mediante os testes estatísticos para que se possa avaliar o grau de significância desta eventual alteração. Diante desse contexto, muitos métodos estatísticos podem ser utilizados, sendo que a escolha de cada um deles dependerá do tipo de mudança ocorrida, do conhecimento ou desconhecimento do ponto de mudança na série e das suposições feitas para cada amostra de dados.

No entender de Naghettini e Pinto (2007), os testes estatísticos podem ser classificados em paramétricos e não paramétricos. Diz-se que um teste é paramétrico se os dados amostrais, por premissa, são obtidos a partir de uma população normal, ou ainda de qualquer outra população cujo modelo de distribuição seja conhecido ou previamente especificado. Em contrapartida, um teste não paramétrico é aquele que não necessita de especificação prévia do modelo distributivo da população, sendo formulado com base em características da amostra como, por exemplo, ordens de classificação ou número de diferenças positivas ou negativas entre os dados trabalhados.

Como comentado anteriormente, cada série temporal dos parâmetros climáticos considerados no presente levantamento foi submetida aos métodos paramétricos, por meio de Análises da Regressão Linear, e não paramétricos, aplicando os testes de Mann-Kendall ("teste M-K”) e de Pettitt (“teste Pett.”) (BACK, 2001).

Utilizou-se a Análise de Regressão Linear para verificar o comportamento da variabilidade de uma determinada série temporal por meio da significância do coeficiente angular de uma reta ajustada às medições. Para tanto, realizou-se o cálculo das médias móveis, empregando ordem cinco aos dados e, em seguida, trabalhou-se com a suavização desses, visando evitar ou minimizar possíveis flutuações dos mesmos.

Esse teste permite verificar alterações de um determinado parâmetro climático por meio da significância do coeficiente angular, assim: $a>0$ significa que a série possui tendência crescente; $a<0$ indica que tendência é decrescente e caso $a \approx 0$ interpreta-se um comportamento estável para a série avaliada. Ao realizar esse procedimento, o valor do coeficiente $R^{2}$ é devolvido como uma medida da qualidade do ajuste efetuado, assim como o intervalo de confiança em $95 \%$ acima e abaixo do valor estimado do coeficiente angular da reta de regressão. 
O teste sequencial de Mann Kendall (MANN, 1945; KENDALL, 1975) é uma análise estatística não paramétrica que considera a hipótese de estabilidade de uma série cuja sucessão de valores ocorre de forma independente, sendo que a distribuição de probabilidade deve permanecer sempre a mesma (série aleatória simples).

Moraes et al. (1995) e Back (2001) descreveram esse método considerando uma série temporal da variável de interesse $Y_{i}$ com $N$ termos, sendo $1 \leq i \leq N$. Realiza-se a soma $t_{n}=\sum_{i=1}^{N} m_{i}$ do número de termos $m_{i}$ da série, relativo ao valor $Y_{i}$ cujos termos precedentes $(j<i)$ são inferiores ao mesmo $\left(Y_{j}<Y_{i}\right)$. Verifica-se que para séries com grande número de termos $(N)$, sob a hipótese nula $\left(H_{0}\right)$ e ausência de tendência, $t_{n}$ apresentará uma distribuição normal com média e variância dada respectivamente por:

$$
\begin{aligned}
& E\left(t_{n}\right)=\frac{N(N-1)}{4} \\
& \operatorname{Var}\left(t_{n}\right)=\frac{N(N-1)(2 N+5)}{18}
\end{aligned}
$$

Testando a significância estatística de $t_{n}$ para a hipótese nula e usando um teste bilateral, esta pode ser rejeitada para grandes valores da estatística $U\left(t_{n}\right)$, fornecida pela equação:

$$
U\left(t_{n}\right)=\frac{\left(t_{n}-E\left(t_{n}\right)\right)}{\sqrt{\operatorname{Var}\left(t_{n}\right)}}
$$

Em seguida, calcula-se a probabilidade $\alpha_{1}$ por meio de uma tabela de distribuição normal reduzida, de forma que $\alpha_{1}=\operatorname{prob} \cdot\left(|U|>\left|U\left(t_{n}\right)\right|\right)$. Sendo $\alpha_{0}$ o nível de significância do teste, a hipótese nula é aceita se $\alpha_{1}>\alpha_{0}$.

Caso a hipótese nula seja rejeitada, implicará a existência de tendência significativa, sendo que o sinal da estatística $U\left(t_{n}\right)$ indica se a tendência é decrescente $\left(U\left(t_{n}\right)<0\right)$ ou então crescente $\left(U\left(t_{n}\right)>0\right)$. Neste caso, em sua versão sequencial, a equação $U\left(t_{n}\right)$ é calculada no sentido direto da série, partindo do valor $i=1$ até $i=N$, gerando a estatística $-1,65<U\left(t_{n}\right)<+1,96$, sendo os valores dos intervalos bilaterais $-1,65 \mathrm{a}+1,65 \mathrm{e}-1,96 \mathrm{a}+1,96$ correspondentes a $\alpha_{0}=0,10$ (em 10\%) e $\alpha_{0}=0,5$ (em 5\%), respectivamente (MORTATTI et al., 2004).

O ponto de início de uma mudança na série pode ser determinado aplicando-se o mesmo princípio à série inversa. De forma análoga, porém no sentido inverso da série temporal original, ao partir do valor $i=N$ até $i=1$, gera-se a estatística inversa $U^{*}\left(t_{n}\right)$. A intersecção das curvas estatísticas $U\left(t_{n}\right)$ e $U^{*}\left(t_{n}\right)$ fornece a localização do ponto aproximado de mudança de tendência. Entretanto, isso apenas será significativo caso este ponto ocorra dentro do intervalo de significância bilateral, isto é, entre - 1,65 e $+1,96$.

O teste de Pettitt (Pettitt, 1979), também descrito por Moraes et al. (1995) e Back (2001), verifica se duas amostras $Y_{1}, \ldots, Y_{t}$ e $Y_{t+1}, \ldots, Y_{T}$ são pertencentes à mesma população. Trata-se de um teste estatístico que identifica o ponto de descontinuidade de uma série temporal (YU et al., 2006). Neste caso, a estatística $U_{t, T}$ é realizada por meio de uma contagem do número de vezes que um membro da primeira amostra é maior que um membro da segunda amostra, o que pode ser escrita de acordo com a equação: 


$$
U_{t, T}=U_{t-1, T}+\sum_{j=1}^{T} \operatorname{sgn}\left(Y_{i}-Y_{j}\right) \quad t=2, . ., T
$$

em que: $\operatorname{sgn}(x)=1$ para $x>0 ; \operatorname{sgn}(x)=0$ para $x=0$ e $\operatorname{sgn}(x)=-1$ para $x<0$.

A partir desta prerrogativa a estatística $U_{t, T}$ é então calculada para valores de $1 \leq t \leq T$ e, na sequência, obtém-se a estatística $K(t)$ do teste por intermédio do máximo valor absoluto de $U_{t, T}$ . É com o valor máximo de $K(t)$ que se localiza o ponto $t$ em que ocorre a mudança brusca na média da série temporal, sendo que sua significância pode ser avaliada por intermédio da equação:

$$
p \cong 2 \cdot e^{\left(\frac{-6 \cdot K(t)^{2}}{T^{3}-T^{2}}\right)}
$$

Além do ponto de mudança brusca $t$, ao realizar a inversão da equação anterior é possível inferir os valores críticos (mínimo ou máximo) de $K(t)$ usando a equação:

$$
K_{\text {crit. }}= \pm \sqrt{\frac{-\mathrm{h}(p / 2) \cdot\left(T^{3}+T^{2}\right)}{6}}
$$

Neste teste os níveis de significância da mudança foram também estimados para 5\% e 10\% do valor de $K_{\text {crit. }}$.

De acordo com Yue et al. (2002), estes testes têm sido largamente utilizados em diversas partes do globo terrestre para a detecção de tendências em séries meteorológicas e hidrológicas. Khaliq et al. (2009) afirmam que métodos não paramétricos são empregados na grande maioria dos estudos de detecção estatística de alterações climáticas e em estudos ambientais.

\section{Resultados e discussão}

Foram realizados os cálculos dos ajustes da linha de tendência e Análise de Regressão Linear utilizando médias móveis e suavizações de todas as séries temporais informadas na Figura 1 e Tabela 1. Posteriormente, com o intuito de constituir uma ferramenta adicional de interpretação estatística, foram gerados os gráficos das variabilidades das séries visando identificar as características e peculiaridades de cada uma, tais como a eventual existência de heterogeneidades e mudanças abruptas.

Devido ao espaço dedicado a este trabalho, uma ênfase maior foi dada aos resultados das aplicações dos métodos estatísticos M-K e de Pett.

Formas gráficas dos “testes M-K e Pett." foram obtidas para todas as variáveis climáticas das localidades trabalhadas neste levantamento. A título de exemplificação, alguns gráficos desses testes foram selecionados e são mostrados nas Figuras 2 e 3 que revelam algumas evidências ou não de tendências. Nesses gráficos respeitou-se os critérios dos intervalos de significância, isto é, para o "teste M-K" as linhas horizontais pontilhadas e tracejadas indicam os níveis de significâncias de $\pm 5 \%$ a $\pm 10 \%$, com os valores dos intervalos bilaterais $-1,96$ a $+1,96$ e -1,65 a $+1,65$, respectivamente, enquanto que para o "teste Pett." as linhas horizontais pontilhadas e tracejadas correspondem aos níveis de significância de mudança que foram estimados para 5\% e $10 \%$ do valor calculado de $K_{\text {crit. }}$ (equação 6). 
Ressalta-se que, no "teste M-K”, a tendência é significativa quando os valores absolutos de $U\left(t_{n}\right)$ são maiores que os intervalos de confiança e o início dessa tendência podem ser identificados pela intersecção das curvas $U\left(t_{n}\right)$ (em traçado contínuo) e $U^{*}\left(t_{n}\right)$ (em traçado pontilhado), representadas na parte inferior dos gráficos da figura a seguir. Porém isso deve ocorrer dentro dos valores críticos dos intervalos de confiança (GROPPO et al., 2001).

No caso do "teste Pett.", que se apresenta na parte superior dos gráficos das Figuras 2 e 3, fez-se o mesmo procedimento da notação do teste anterior. Porém, neste teste o ponto de mudança brusca de $K(t)$, tomado em módulo, ocorre quando este for maior que os limites críticos estabelecidos de 5\% e 10\%. No entanto, essa condição deixa de ser verdadeira quando os valores que estão em seguida ao valor crítico oscilam em intervalos próximos ao valor máximo. Nesta situação, o último valor do intervalo de oscilação indica o ponto de início da tendência (Pettitt 1979).

Nos dois testes em evidência utilizou-se a seguinte convenção: tendência positiva confirmada entre $5 \%$ e $10 \%$ dos níveis dos intervalos de confianças $(+)(+)$; acima de $10 \%$ do nível do intervalo de confiança $(+)$, de maneira análoga, $(-)(-)$ e $(-)$ para tendência negativa confirmada, respectivamente. Caso não houvesse condições de confirmar tendência o sinal (?) foi adotado.

Para a cidade de Taguatinga (TO), entre 1961 e 2015, confirmou-se uma tendência positiva $(+)(+)$ para a T-máx. em 1986, visto que aplicando o "teste M-K" registrou-se um cruzamento das curvas estatísticas $U\left(t_{n}\right)$ e $U^{*}\left(t_{n}\right)$ entre os intervalos de confiança em 1990 (Figura 2a, inferior). Esse fato representa o indício de haver tendência dessa variável climática. Essa evidência ficou confirmada ao aplicar o "teste Pett." (Figura 2a, superior), que apresentou a quebra de tendência $(+)(+)$ confirmada no ano de 1986. Comportamento análogo ocorreu com a cidade de Cametá (Figura 2b), porém para a T-min. entre 1970 e 2015, que passou a ter tendência $(+)(+)$ significativa confirmada nos dois testes a partir de 1996.

Entretanto, como mostrado na Figura 2c, na localidade de São Gabriel da Cachoeira, entre 1961 e 2015, foi inferida tendência negativa $(-)(-)$ na T-mín. a partir de 1995. Para os dados medidos nesta estação, o "teste M-K” acusou cruzamentos das curvas estatísticas em 1997, enquanto que a curva da estatística $K(t)$ do "teste Pett." cruzou os níveis de significâncias em 1995, confirmando o início da tendência de queda da T-mín. nesta data. 
Figura 2 - Testes de Mann-Kendall (inferior e em preto) e Pettitt (superior e em vermelho) aplicados aos dados apresentando diferentes situações quanto a tendência em: (a) Taguatinga, para T-máx.; (b) Cametá, para T-mín. e (c) São Gabriel da Cachoeira, para T-mín

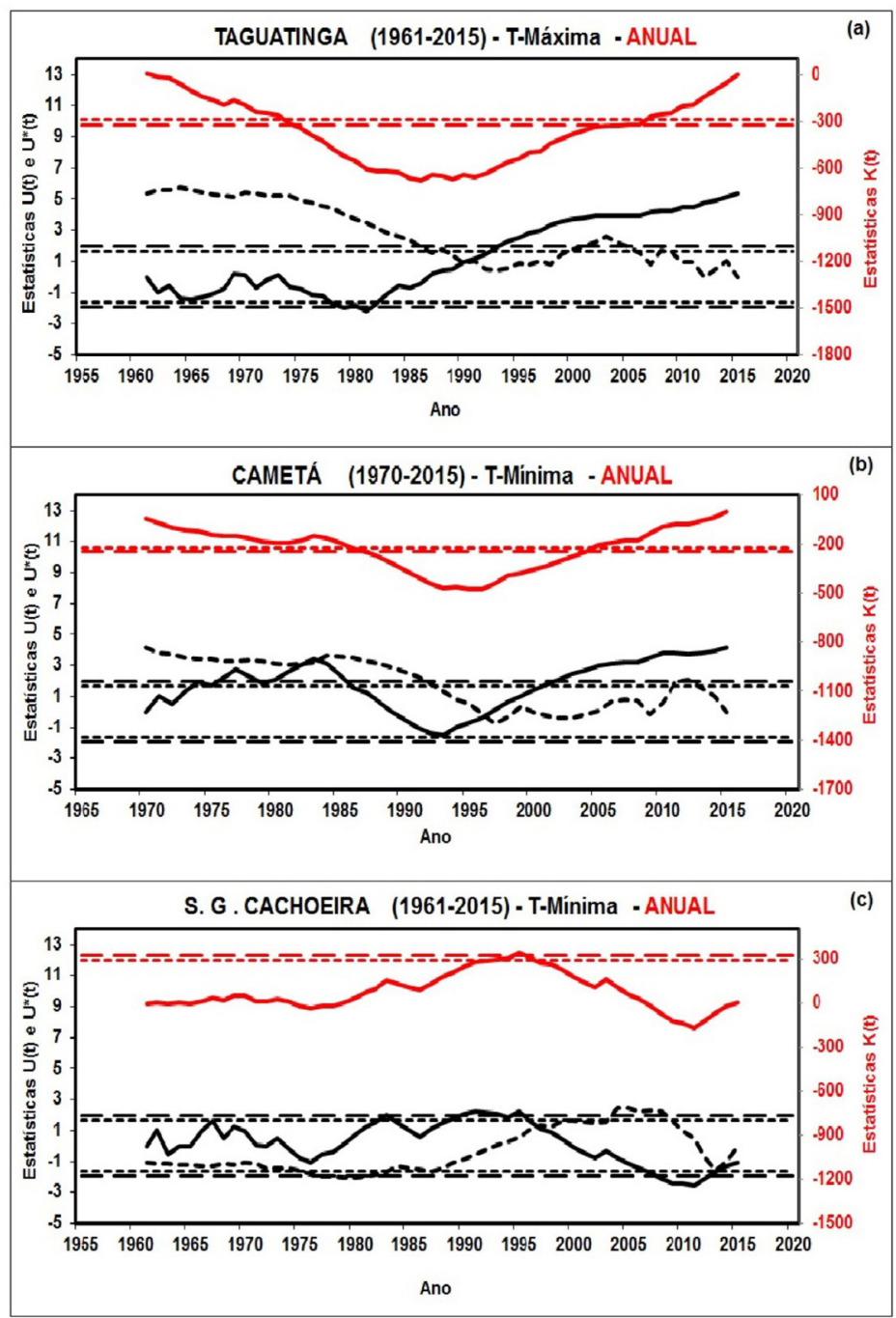

Fonte: Elaborada pelos próprios autores.

Com relação ao índice de Prec. medido na cidade de Barcelos no período de 1961 a 2015, a aplicação dos testes não paramétricos estão mostrados na Figura 3a. Para essa localidade, o "teste M-K" registrou um cruzamento das curvas estatísticas $U\left(t_{n}\right)$ e $U^{*}\left(t_{n}\right)$ entre os intervalos de confiança em 1973, entretanto o "teste Pett." apresentou a quebra de tendência $(-)(-)$ confirmada no ano de 1976, indicam uma tendência negativa a partir deste ano para aquela cidade amazonense.

Em contrapartida, apesar dos cruzamentos revelados na Figura 3b (inferior) para as curvas estatísticas no "teste M-K", não se pode confirmar tendência na Prec. medida em Manaus entre 1961 e 2015, visto que a curva da estatística $K(t)$ do "teste Pett." (Figura 3b, superior) não cruzou nenhum dos níveis de significância. De forma análoga, a Figura 3c revelou que para Macapá, no período de 1968 a 2015, nenhuma tendência pode ser confirmada para as medições na T-méd., uma vez que nenhum cruzamento das curvas estatísticas no "teste $\mathrm{M}-\mathrm{K}$ " ocorreu entre os intervalos de confiança de $\pm 5 \%$ e $\pm 10 \%$, em que pese a curva $K(t)$ do "teste Pett." ter cruzado os dois níveis de significância. 
Figura 3 - Idem a figura anterior, mas aplicados aos dados de: (a) Barcelos, para Prec.; (b) Manaus, para Prec. e (c) Macapá, para T-méd.

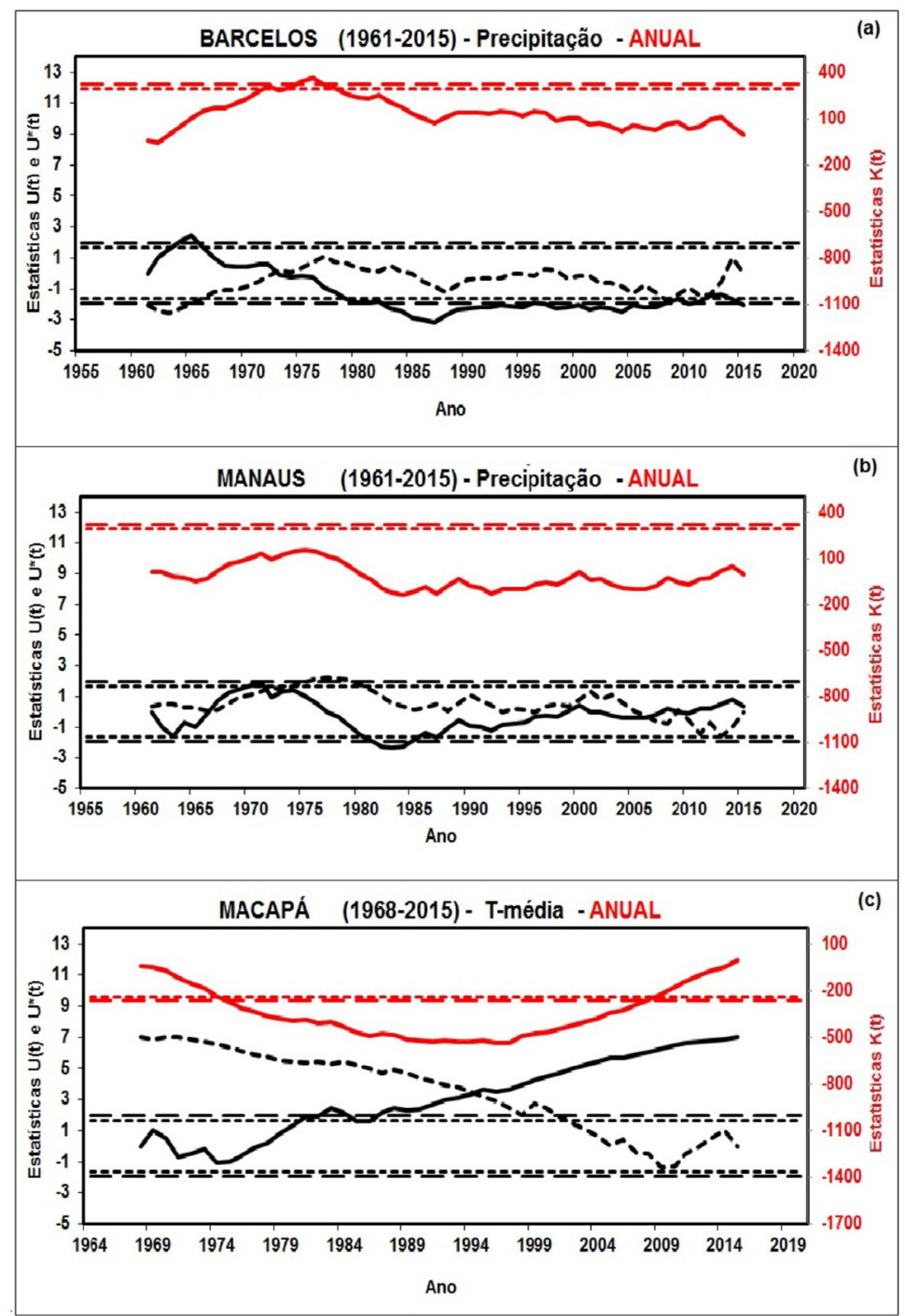

Fonte: Elaborada pelos próprios autores.

Devido à grande quantidade de informações numéricas obtidas, a seguir são apresentados resultados estatísticos em forma de tabelas, além de mapas contendo as distribuições de tendências inferidas para as quatro variáveis climáticas abordadas no presente trabalho.

A Tabela 2 resume todas as análises não paramétricas efetuadas nas séries temporais das localidades abordadas neste levantamento, tendo sido utilizada mesma convecção anterior, ou seja, $(+)(+)$ e $(-)(-)$ quando a tendência positiva e negativa for confirmada entre $5 \%$ e $10 \%$ dos níveis dos intervalos de confianças, respectivamente. De forma análoga, $(+)$ e $(-)$ quando a tendência for confirmada acima de $10 \%$ do nível do intervalo de confiança, respectivamente. Nestes casos, para cada teste também foi incluído em parênteses o ano da ocorrência. Em situações que não houvesse condições de confirmar tendência decidiu-se adotar o símbolo de interrogação (?). 
Tabela 2 - Síntese das análises estatísticas empregando os testes de MannKendall e de Pettitt para variáveis climáticas da região norte do Brasil

\begin{tabular}{|c|c|c|c|c|}
\hline $\begin{array}{l}\text { Cidade- Estado } \\
\text { (Período) }\end{array}$ & Série & $\begin{array}{l}\text { Mann- } \\
\text { Kendall }\end{array}$ & Pettitt & Tendência \\
\hline \multirow{4}{*}{$\begin{array}{c}\text { Altamira- PA } \\
(1961-2015)\end{array}$} & T-mín. & $?$ & $(+)(+) 2000$ & $?$ \\
\hline & T-máx. & $?$ & $(+)(+) 1991$ & $?$ \\
\hline & T-méd. & $?$ & $(+)(+) 1986$ & $?$ \\
\hline & Prec. & $?$ & (+) 1983 & $?$ \\
\hline \multirow{4}{*}{$\begin{array}{l}\text { Araguaína-TO } \\
(1984-2015)\end{array}$} & T-mín. & $(+)(+) 1997$ & $(+)(+) 1997$ & $(+)(+) 1997$ \\
\hline & T-máx. & $(+)(+) 1998$ & $(+)(+) 1994$ & $(+)(+) 1994$ \\
\hline & T-méd. & $(+)(+) 1997$ & $(+)(+) 1996$ & $(+)(+) 1996$ \\
\hline & Prec. & ? & ? & ? \\
\hline \multirow{4}{*}{$\begin{array}{c}\text { Barcelos- AM } \\
(1961-2015)\end{array}$} & T-mín. & $(+)(+) 1998$ & $(+)(+) 1994$ & $(+)(+) 1994$ \\
\hline & T-máx. & $(+)(+) 1985$ & $(+)(+) 1985$ & $(+)(+) 1985$ \\
\hline & T-méd. & $(+)(+) 1995$ & $(+)(+) 1993$ & $(+)(+) 1993$ \\
\hline & Prec. & $(-)(-) 1973$ & $(-)(-) 1976$ & $(-)(-) 1976$ \\
\hline \multirow{4}{*}{$\begin{array}{l}\text { Belém- PA } \\
(1961-2015)\end{array}$} & T-mín. & $(+)(+) 1994$ & $(+)(+) 1992$ & $(+)(+) 1992$ \\
\hline & T-máx. & $(+)(+) 2002$ & $(+)(+) 1996$ & $(+)(+) 1996$ \\
\hline & T-méd. & $(+)(+) 1997$ & $(+)(+) 1994$ & $(+)(+) 1994$ \\
\hline & Prec. & $(+)(+) 2005$ & $(+)(+) 2004$ & $(+)(+) 2004$ \\
\hline \multirow{4}{*}{$\begin{array}{l}\text { Belterra- PA } \\
(1972-2015)\end{array}$} & T-mín. & $(+)(+) 2000$ & $(+)(+) 1996$ & $(+)(+) 1996$ \\
\hline & T-máx. & $(+)(+) 2003$ & $(+)(+) 1995$ & ? \\
\hline & T-méd. & $(+)(+) 2003$ & $(+)(+) 1999$ & $(+)(+) 1999$ \\
\hline & Prec. & $(+)(+) 2006$ & ? & ? \\
\hline \multirow{4}{*}{$\begin{array}{c}\text { Benjamin Constant- } \\
\text { AM } \\
(1961-2015)\end{array}$} & T-mín. & $(+)(+) 1999$ & $(+)(+) 1997$ & $(+)(+) 1997$ \\
\hline & T-máx. & $(+)(+) 1989$ & $(+)(+) 1986$ & $(+)(+) 1986$ \\
\hline & T-méd. & $?$ & $(+)(+) 1987$ & ? \\
\hline & Prec. & $(-)(-) 1967$ & $(-)(-) 1978$ & $?$ \\
\hline \multirow{4}{*}{$\begin{array}{c}\text { Boa Vista- RR } \\
(1993-2015)\end{array}$} & T-mín. & (+) 2012 & $?$ & $?$ \\
\hline & T-máx. & $?$ & $(+)(+) 2002$ & ? \\
\hline & T-méd. & (+) 2006 & $(+)(+) 2004$ & $(+)(+) 2004$ \\
\hline & Prec. & ? & ? & ? \\
\hline \multirow{4}{*}{$\begin{array}{l}\text { Breves- PA } \\
(1995-2015)\end{array}$} & T-mín. & $(+)(+) 2005$ & $(+)(+) 2004$ & $(+)(+) 2004$ \\
\hline & T-máx. & $(+)(+) 2002$ & $(+)(+) 2004$ & $(+)(+) 2004$ \\
\hline & T-méd. & $(+)(+) 2003$ & $(+)(+) 2004$ & $(+)(+) 2004$ \\
\hline & Prec. & $(-)(-) 2009$ & ? & ? \\
\hline \multirow{4}{*}{$\begin{array}{l}\text { Cametá- PA } \\
(1970-2015)\end{array}$} & T-mín. & $(+)(+) 1996$ & $(+)(+) 1996$ & $(+)(+) 1996$ \\
\hline & T-máx. & $(+)(+) 2005$ & $(+)(+) 1996$ & ? \\
\hline & T-méd. & $(+)(+) 2002$ & $(+)(+) 1996$ & $?$ \\
\hline & Prec. & $?$ & ? & $?$ \\
\hline \multirow{4}{*}{$\begin{array}{l}\text { Caracaraí- PA } \\
(1978-2015)\end{array}$} & T-mín. & (+) 2009 & $(+)(+) 2000$ & $?$ \\
\hline & T-máx. & $(+)(+) 1990$ & $(+)(+) 1997$ & $?$ \\
\hline & T-méd. & $(+)(+) 2001$ & $(+)(+) 1997$ & $(+)(+) 1997$ \\
\hline & Prec. & $(+)(+) 1988$ & $(+)(+) 1989$ & $(+)(+) 1989$ \\
\hline \multirow{4}{*}{$\begin{array}{c}\text { Coari- AM } \\
(1970-2015)\end{array}$} & T-mín. & $(+)(+) 2005$ & $(+)(+) 1997$ & $?$ \\
\hline & T-máx. & $(+)(+) 1997$ & $(+)(+) 2000$ & $(+)(+) 2000$ \\
\hline & T-méd. & $(+)(+) 2002$ & $(+)(+) 1996$ & $?$ \\
\hline & Prec. & ? & ? & ? \\
\hline \multirow{4}{*}{$\begin{array}{c}\text { Codajás- AM } \\
(1993-2015)\end{array}$} & T-mín. & $(+)(+) 2001$ & $(+)(+) 2001$ & $(+)(+) 2001$ \\
\hline & T-máx. & $(+)(+) 1999$ & $(+)(+) 1999$ & $(+)(+) 1999$ \\
\hline & T-méd. & $(+)(+) 1997$ & $(+)(+) 2000$ & $(+)(+) 2000$ \\
\hline & Prec. & ? & ? & ? \\
\hline \multirow{4}{*}{$\begin{array}{c}\text { Conceição do } \\
\text { Araguaia- PA } \\
(1961-2015)\end{array}$} & T-mín. & $?$ & $(+)(+) 1986$ & $?$ \\
\hline & T-máx. & $?$ & $(+)(+) 1986$ & $?$ \\
\hline & T-méd. & $?$ & $(+)(+) 1986$ & $?$ \\
\hline & Prec. & $?$ & ? & $?$ \\
\hline
\end{tabular}


Tabela 2 - Síntese das análises estatísticas empregando os testes de MannKendall e de Pettitt para variáveis climáticas da região norte do Brasil (continuação)

\begin{tabular}{|c|c|c|c|c|}
\hline $\begin{array}{l}\text { Cruzeiro do Sul- AC } \\
\qquad(1970-2015)\end{array}$ & $\begin{array}{l}\text { T-mín. } \\
\text { T-máx. } \\
\text { T-méd. } \\
\text { Prec. }\end{array}$ & $\begin{array}{c}(+) 1996 \\
(+)(+) 1984 \\
(+) 1992 \\
? \\
?\end{array}$ & $\begin{array}{c}(+)(+) 1994 \\
(+)(+) 1991 \\
(+)(+) 1991 \\
\text { ? }\end{array}$ & $\begin{array}{c}(+)(+) 1994 \\
? \\
(+)(+) 1991 \\
?\end{array}$ \\
\hline $\begin{array}{l}\text { Eirunepé- AM } \\
(1993-2015)\end{array}$ & $\begin{array}{c}\text { T-mín. } \\
\text { T-máx. } \\
\text { T-méd. } \\
\text { Prec. }\end{array}$ & $\begin{array}{c}(+)(+) 1997 \\
(+)(+) 1998 \\
(+)(+) 1999 \\
\text { ? }\end{array}$ & $\begin{array}{c}(+)(+) 1999 \\
(+)(+) 2000 \\
(+)(+) 2000 \\
\text { ? }\end{array}$ & $\begin{array}{c}(+)(+) 1999 \\
(+)(+) 2000 \\
(+)(+) 2000 \\
?\end{array}$ \\
\hline $\begin{array}{c}\text { Fonte Boa- AM } \\
(1990-2015)\end{array}$ & $\begin{array}{c}\text { T-mín. } \\
\text { T-máx. } \\
\text { T-méd. } \\
\text { Prec. }\end{array}$ & $\begin{array}{c}(+)(+) 1997 \\
(+)(+) 1998 \\
(+)(+) 1999 \\
\text { ? }\end{array}$ & $\begin{array}{c}(+)(+) 1999 \\
(+)(+) 2000 \\
(+)(+) 2000 \\
\text { ? }\end{array}$ & $\begin{array}{c}(+)(+) 1999 \\
(+)(+) 2000 \\
(+)(+) 2000 \\
?\end{array}$ \\
\hline $\begin{array}{c}\text { Iauaretê- AM } \\
(1970-2015)\end{array}$ & $\begin{array}{c}\text { T-mín. } \\
\text { T-máx. } \\
\text { T-méd. } \\
\text { Prec. }\end{array}$ & $\begin{array}{c}(+)(+) 2013 \\
\text { ? } \\
(+)(+) 2000 \\
(-)(-) 1973\end{array}$ & $\begin{array}{c}(+)(+) 2001 \\
(+)(+) 1994 \\
(+)(+) 1999 \\
(-) 1977\end{array}$ & $\begin{array}{c}? \\
? \\
(+)(+) 1999 \\
(-) 1977 \\
\end{array}$ \\
\hline $\begin{array}{l}\text { Itacoatiara- AM } \\
(1971-2015)\end{array}$ & $\begin{array}{c}\text { T-mín. } \\
\text { T-máx. } \\
\text { T-méd. } \\
\text { Prec. }\end{array}$ & $\begin{array}{c}? \\
(+)(+) 1993 \\
(+)(+) 2001 \\
?\end{array}$ & $\begin{array}{c}(+)(+) 1993 \\
(+)(+) 1994 \\
(+)(+) 1993 \\
\text { ? }\end{array}$ & $\begin{array}{c}? \\
(+)(+) 1994 \\
? \\
?\end{array}$ \\
\hline $\begin{array}{l}\text { Itaituba- PA } \\
(1966-2015)\end{array}$ & $\begin{array}{c}\text { T-mín. } \\
\text { T-máx. } \\
\text { T-méd. } \\
\text { Prec. }\end{array}$ & $\begin{array}{c}\text { ? } \\
(+)(+) 1995 \\
? \\
(-)(-) 1981\end{array}$ & $\begin{array}{l}c_{(+)}(+) 2000 \\
(+)(+) 1991 \\
(+)(+) 1991 \\
(-)(-) 1985\end{array}$ & $\begin{array}{c}\text { ? } \\
(+)(+) 1991 \\
? \\
(-)(-) 1985\end{array}$ \\
\hline $\begin{array}{l}\text { Lábrea- AM } \\
(1993-2015)\end{array}$ & $\begin{array}{c}\text { T-mín. } \\
\text { T-máx. } \\
\text { T-méd. } \\
\text { Prec. }\end{array}$ & $\begin{array}{l}(+)(+) 2000 \\
(+)(+) 2004 \\
(+)(+) 2008 \\
(-)(-) 2003\end{array}$ & $\begin{array}{l}(+)(+) 2001 \\
(+)(+) 2004 \\
(+)(+) 2007 \\
(-)(-) 2003\end{array}$ & $\begin{array}{c}(+)(+) 2001 \\
(+)(+) 2004 \\
(+)(+) 2007 \\
(-)(-) 2003\end{array}$ \\
\hline $\begin{array}{l}\text { Macapá- AP } \\
(1968-2015)\end{array}$ & $\begin{array}{c}\text { T-mín. } \\
\text { T-máx. } \\
\text { T-méd. } \\
\text { Prec. }\end{array}$ & $\begin{array}{l}? \\
? \\
? \\
?\end{array}$ & $\begin{array}{c}(+)(+) 1996 \\
(+)(+) 1990 \\
(+)(+) 1997 \\
?\end{array}$ & $\begin{array}{l}? \\
? \\
? \\
?\end{array}$ \\
\hline $\begin{array}{c}\text { Manaus- AM } \\
(1961-2015)\end{array}$ & $\begin{array}{c}\text { T-mín. } \\
\text { T-máx. } \\
\text { T-méd. } \\
\text { Prec. }\end{array}$ & $\begin{array}{c}\text { ? } \\
(+)(+) 2004 \\
? \\
?\end{array}$ & $\begin{array}{c}(+)(+) 2000 \\
(+)(+) 1996 \\
(+)(+) 2000 \\
\text { ? }\end{array}$ & $\begin{array}{l}\text { ? } \\
? \\
? \\
?\end{array}$ \\
\hline $\begin{array}{c}\text { Manicoré- AM } \\
(1993-2015)\end{array}$ & $\begin{array}{c}\text { T-mín. } \\
\text { T-máx. } \\
\text { T-méd. } \\
\text { Prec. }\end{array}$ & $\begin{array}{c}(+) 2012 \\
(+) 2002 \\
(+) 2007 \\
(+)(+) 2008 \\
\end{array}$ & $\begin{array}{c}(+)(+) 2008 \\
(+)(+) 2002 \\
(+)(+) 2006 \\
?\end{array}$ & $\begin{array}{c}(+)(+) 2008 \\
(+)(+) 2002 \\
(+)(+) 2006 \\
?\end{array}$ \\
\hline $\begin{array}{l}\text { Marabá- PA } \\
(1973-2015)\end{array}$ & $\begin{array}{c}\text { T-mín. } \\
\text { T-máx. } \\
\text { T-méd. } \\
\text { Prec. }\end{array}$ & $\begin{array}{l}? \\
? \\
? \\
?\end{array}$ & $\begin{array}{c}(+)(+) 1994 \\
(+)(+) 1986 \\
(+)(+) 1991 \\
\text { ? }\end{array}$ & $\begin{array}{l}? \\
? \\
? \\
?\end{array}$ \\
\hline $\begin{array}{c}\text { Monte Alegre- PA } \\
\quad(1975-2015)\end{array}$ & $\begin{array}{c}\text { T-mín. } \\
\text { T-máx. } \\
\text { T-méd. } \\
\text { Prec. }\end{array}$ & $\begin{array}{c}(+)(+) 1992 \\
(+)(+) 2009 \\
(+)(+) 1994 \\
\text { ? }\end{array}$ & $\begin{array}{c}(+)(+) 1994 \\
(+)(+) 1996 \\
(+)(+) 1994 \\
\text { ? }\end{array}$ & $\begin{array}{c}(+)(+) 1994 \\
? \\
(+)(+) 1994 \\
?\end{array}$ \\
\hline $\begin{array}{l}\text { Óbidos- PA } \\
(1970-2015)\end{array}$ & $\begin{array}{c}\text { T-mín. } \\
\text { T-máx. } \\
\text { T-méd. } \\
\text { Prec. }\end{array}$ & $\begin{array}{c}(+) 2001 \\
(+)(+) 2003 \\
(+)(+) 1997 \\
?\end{array}$ & $\begin{array}{c}(+)(+) 2000 \\
(+) 2001 \\
(+)(+) 1994 \\
?\end{array}$ & $\begin{array}{c}(+)(+) 2000 \\
(+) 2001 \\
(+)(+) 1994 \\
?\end{array}$ \\
\hline $\begin{array}{l}\text { Palmas- TO } \\
(1994-2015)\end{array}$ & $\begin{array}{c}\text { T-mín. } \\
\text { T-máx. } \\
\text { T-méd. } \\
\text { Prec. }\end{array}$ & 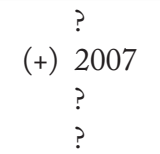 & $\begin{array}{c}(+)(+) 2004 \\
(+)(+) 2006 \\
(+)(+) 2004 \\
?\end{array}$ & $\begin{array}{c}? \\
(+)(+) \\
\text { ? } \\
? \\
?\end{array}$ \\
\hline
\end{tabular}


Tabela 2 - Síntese das análises estatísticas empregando os testes de MannKendall e de Pettitt para variáveis climáticas da região norte do Brasil (conclusão)

\begin{tabular}{|c|c|c|c|c|}
\hline $\begin{array}{c}\text { Cidade- Estado } \\
\text { (Período) }\end{array}$ & Série & $\begin{array}{c}\text { Mann- } \\
\text { Kendall } \\
\end{array}$ & Pettitt & Tendência \\
\hline $\begin{array}{l}\text { Parintins- AM } \\
(1993-2015)\end{array}$ & $\begin{array}{l}\text { T-mín. } \\
\text { T-máx. } \\
\text { T-méd. } \\
\text { Prec. }\end{array}$ & $\begin{array}{c}(+)(+) 2004 \\
? \\
? \\
(+)(+) 2003 \\
? \\
?\end{array}$ & $\begin{array}{c}(+)(+) 2003 \\
\quad ? \\
\text { ? } \\
(+) \\
\quad 2003 \\
\quad ? \\
\end{array}$ & $\begin{array}{c}(+)(+) 2003 \\
\quad ? \\
(+) \\
2003 \\
?\end{array}$ \\
\hline $\begin{array}{l}\text { Pedro Afonso- TO } \\
\quad(1977-2015)\end{array}$ & $\begin{array}{l}\text { T-mín. } \\
\text { T-máx. } \\
\text { T-méd. } \\
\text { Prec. }\end{array}$ & $\begin{array}{c}(+)(+) \\
? \\
? \\
? \\
? \\
?\end{array}$ & $\begin{array}{c}(+)(+) 2001 \\
(+)(+) 1997 \\
(+)(+) 1997 \\
?\end{array}$ & $\begin{array}{c}(+)(+) \\
? \\
? \\
? \\
? \\
\end{array}$ \\
\hline $\begin{array}{l}\text { Peixe- TO } \\
(1975-2015)\end{array}$ & $\begin{array}{l}\text { T-mín. } \\
\text { T-máx. } \\
\text { T-méd. } \\
\text { Prec. }\end{array}$ & $\begin{array}{l}(+)(+) 1985 \\
(+)(+) 1993 \\
(+)(+) 1989 \\
(-)(-) 2000\end{array}$ & $\begin{array}{l}(+)(+) 1989 \\
(+)(+) 1992 \\
(+)(+) 1992 \\
(-)(-) 2000\end{array}$ & $\begin{array}{l}(+)(+) 1989 \\
(+)(+) 1992 \\
(+)(+) 1992 \\
(-)(-) 2000\end{array}$ \\
\hline $\begin{array}{l}\text { Porto de Moz- PA } \\
\quad(1966-2015)\end{array}$ & $\begin{array}{l}\text { T-mín. } \\
\text { T-máx. } \\
\text { T-méd. } \\
\text { Prec. }\end{array}$ & $\begin{array}{c}? \\
(+)(+) 1994 \\
? \\
(-)(-) 1968\end{array}$ & $\begin{array}{l}\text { (+) }^{(+)} 1995 \\
(+)(+) 1994 \\
(+)(+) 1995 \\
(-)(-) 1974\end{array}$ & $\begin{array}{c}? \\
(+)(+) \\
? \\
? \\
?\end{array}$ \\
\hline $\begin{array}{l}\text { Porto Nacional- TO } \\
\quad(1961-2015)\end{array}$ & $\begin{array}{l}\text { T-mín. } \\
\text { T-máx. } \\
\text { T-méd. } \\
\text { Prec. }\end{array}$ & $\begin{array}{c}? \\
(+)(+) 1995 \\
? \\
?\end{array}$ & $\begin{array}{c}(+)(+) 1986 \\
(+)(+) 1994 \\
(+)(+) 1994 \\
?\end{array}$ & $\begin{array}{c}? \\
(+)(+) 1994 \\
? \\
?\end{array}$ \\
\hline $\begin{array}{l}\text { Rio Branco- AC } \\
(1970-2015)\end{array}$ & $\begin{array}{l}\text { T-mín. } \\
\text { T-máx. } \\
\text { T-méd. } \\
\text { Prec. }\end{array}$ & $\begin{array}{c}(+)(+) 1997 \\
? \\
(+)(+) 1993 \\
(+)(+) 1983\end{array}$ & $\begin{array}{c}(+)(+) 1993 \\
? \\
(+)(+) 1989 \\
(+)(+) 1983 \\
\end{array}$ & $\begin{array}{c}(+)(+) 1993 \\
? \\
(+)(+) 1989 \\
(+)(+) 1983\end{array}$ \\
\hline $\begin{array}{c}\text { São G. Cachoeira- } \\
\text { AM } \\
(1961-2015)\end{array}$ & $\begin{array}{l}\text { T-mín. } \\
\text { T-máx. } \\
\text { T-méd. } \\
\text { Prec. }\end{array}$ & $\begin{array}{c}(-)(-) 1997 \\
? \\
(+)(+) 1980 \\
(+)(+) 1985\end{array}$ & $\begin{array}{l}(-)(-) 1995 \\
(+)(+) 1991 \\
(+)(+) 1979 \\
(+) 1983\end{array}$ & $\begin{array}{c}(-)(-) 1995 \\
? \\
(+)(+) 1979 \\
(+)(+) 1983\end{array}$ \\
\hline $\begin{array}{c}\text { Soure- PA } \\
(1961-2015)\end{array}$ & $\begin{array}{l}\text { T-mín. } \\
\text { T-máx. } \\
\text { T-méd. } \\
\text { Prec. }\end{array}$ & $\begin{array}{c}(+)(+) 1988 \\
? \\
(+)(+) 1998 \\
(-)(-) 2000\end{array}$ & $\begin{array}{c}(+)(+) 1989 \\
? \\
(+)(+) 1997 \\
(-)(-) 2000\end{array}$ & $\begin{array}{c}(+)(+) 1989 \\
? \\
(+)(+) 1997 \\
(-)(-) 2000\end{array}$ \\
\hline $\begin{array}{l}\text { Taguatinga- TO } \\
(1961-2015)\end{array}$ & $\begin{array}{l}\text { T-mín. } \\
\text { T-máx. } \\
\text { T-méd. } \\
\text { Prec. }\end{array}$ & $\begin{array}{c}? \\
(+)(+) \\
? \\
? \\
?\end{array}$ & $\begin{array}{c}(+)(+) 1986 \\
(+)(+) 1986 \\
(+)(+) 1986 \\
?\end{array}$ & $\begin{array}{c}? \\
(+)(+) 1986 \\
? \\
?\end{array}$ \\
\hline $\begin{array}{c}\text { Tarauacá- AC } \\
(1993-2015)\end{array}$ & $\begin{array}{c}\text { T-mín. } \\
\text { T-máx. } \\
\text { T-méd. } \\
\text { Prec. }\end{array}$ & $\begin{aligned} & ? \\
& ? \\
& ? \\
&(+) 2013 \\
& ? \\
&\end{aligned}$ & $\begin{array}{l}\text { ? } \\
\text { ? } \\
(+) \\
2007 \\
\quad ?\end{array}$ & $\begin{array}{ll} & ? \\
& ? \\
(+) & 2007 \\
& ? \\
\end{array}$ \\
\hline $\begin{array}{c}\text { Tefé- AM } \\
(1970-2015)\end{array}$ & $\begin{array}{c}\text { T-mín. } \\
\text { T-máx. } \\
\text { T-méd. } \\
\text { Prec. }\end{array}$ & $\begin{array}{c}(+)(+) 2008 \\
? \\
(+)(+) 2002 \\
?\end{array}$ & $\begin{array}{c}(+)(+) 2001 \\
(+)(+) 1992 \\
(+)(+) 1992 \\
\text { ? }\end{array}$ & $\begin{array}{l}? \\
? \\
? \\
?\end{array}$ \\
\hline $\begin{array}{c}\text { Tracuateuá- PA } \\
(1973-2015)\end{array}$ & $\begin{array}{c}\text { T-mín. } \\
\text { T-máx. } \\
\text { T-méd. } \\
\text { Prec. }\end{array}$ & $\begin{aligned} & ? \\
& ? \\
(+) & 1985 \\
& ?\end{aligned}$ & $\begin{array}{c}\text { ? } \\
(+)(+) 1994 \\
(+)(+) 1986 \\
?\end{array}$ & $\begin{array}{c}\text { ? } \\
? \\
(+)(+) 1986 \\
?\end{array}$ \\
\hline $\begin{array}{l}\text { Tucuruí- PA } \\
(1971-2015)\end{array}$ & $\begin{array}{l}\text { T-mín. } \\
\text { T-máx. } \\
\text { T-méd. } \\
\text { Prec. }\end{array}$ & $\begin{array}{c}\text { ? } \\
(+)(+) 2000 \\
? \\
?\end{array}$ & $\begin{array}{c}(+)(+) 1986 \\
(+)(+) 1996 \\
(+)(+) 1994 \\
?\end{array}$ & $\begin{array}{c}\text { ? } \\
(+)(+) \\
? \\
? \\
?\end{array}$ \\
\hline
\end{tabular}

Fonte: Elaborada pelos próprios autores. 
Como foram tratadas um total de 160 séries temporais nesta pesquisa, a quantidade de informações numéricas é muito grande. Neste sentido, optou-se por elaborar mapas das distribuições espaciais de tendências das variáveis climáticas no referido território brasileiro, como serão apresentados nas Figuras 5 e 6. Cada mapa corresponde a uma determinada grandeza climática trabalhada, sendo possível, por meio de uma análise visual de cada mapeamento, identificar os locais onde se detectaram tendências crescentes (+), decrescentes (-) e a ausências de tendências significativas (?).

\section{Mapas de tendências climáticas}

Como será verificado adiante, as Figuras 5 e 6 mostram os mapas das distribuições espaciais das tendências significativas inferidas para cada variável climática da região norte, lembrando que, pela ausência de estações do INMET, não há ocorrências realizadas no estado de Rondônia. A legenda anexa em cada figura indica o tipo de tendência detectada nessa região brasileira.

De acordo com as informações fornecidas pela Agência Nacional de Águas (ANA), na Figura 4 estão mostrados parte dos rios que compõem a Região Hidrográfica da Amazônia, destacando os rios Solimões, Negro, Amazonas, Juruá, Branco, Acre, Purus, Madeira, Anapu, Xingu, Araguaia e Tocantins (ANA-2,2016). Vale ressaltar que na Região Amazônica não existem apenas os rios citados, apenas foram destacados no mapa dessa figura por estarem próximos às localidades das estações do INMET, cujas medidas foram abordadas nesta pesquisa e mostradas na Figura 1 e Tabelas 1 e 2.

\section{Figura 4 - Mapa da localização de alguns dos rios da Bacia Hidrográfica da Amazônia e das localidades de estações do INMET tratadas neste trabalho}

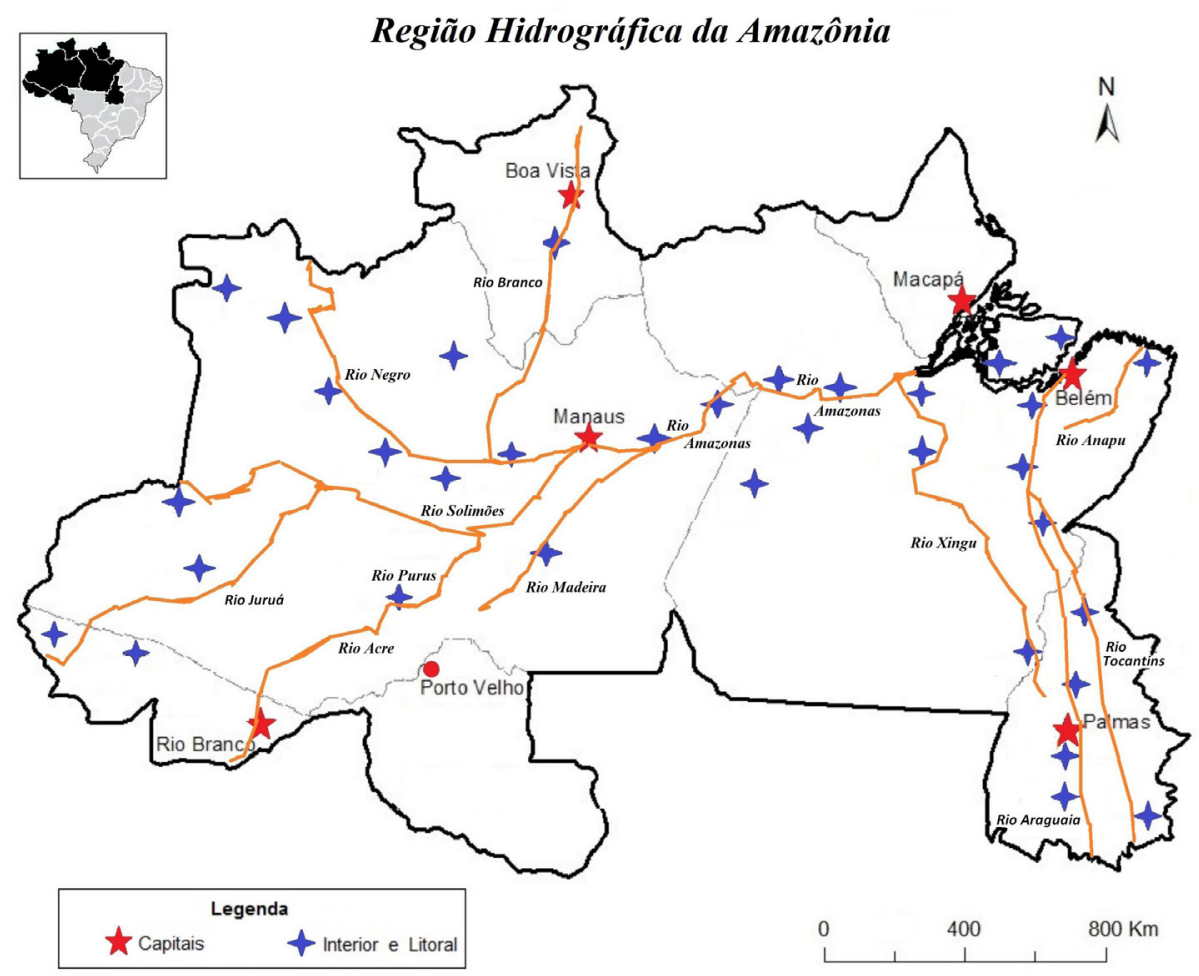

Fonte: Elaborada pelos próprios autores, a partir da adaptação do mapa disponível em ANA-2 (2016). 
A Figura 5, revela as 19 localidades, correspondendo a 48\% da amostra, onde se registraram tendências das séries temporais da T-mín. indicando que em 18 locais avaliados, ou seja, em 45\%, ocorreram registros positivos $(+)(+)$. Por meio da mesma figura evidencia-se que a maioria dessas tendências está localizada nas proximidades dos rios Solimões, Negro, Amazonas e Tocantins. O mapa também acusa a ausência de tendência dessa variável em várias cidades espalhadas por todos os estados que compõem a região norte. Destaca-se ainda a cidade amazonense de São Gabriel da Cachoeira que apresentou a única tendência negativa $(-)(-)$ para a T-mín.

Com relação à distribuição de tendências da $T$-máx., mostrada na Figura $5 b$, constatou-se um menor número de localidades (17) com aumento desse tipo de temperatura $(+)(+)$, quando comparado com o mapa da T-min., sendo que estas estão principalmente localizadas ao longo dos rios Solimões e Amazonas. Nenhum registro de tendência negativa foi inferido ao aplicar os testes não paramétricos nesta variável climática.

Figura 5 - Mapas das distribuições de tendências climáticas na região norte do Brasil para: (a) T-Mín. e (b) T-Máx. Os locais assinalados em forma circular indicam as capitais dos estados, enquanto que os locais representados em losangos indicam cidades do interior ou do litoral

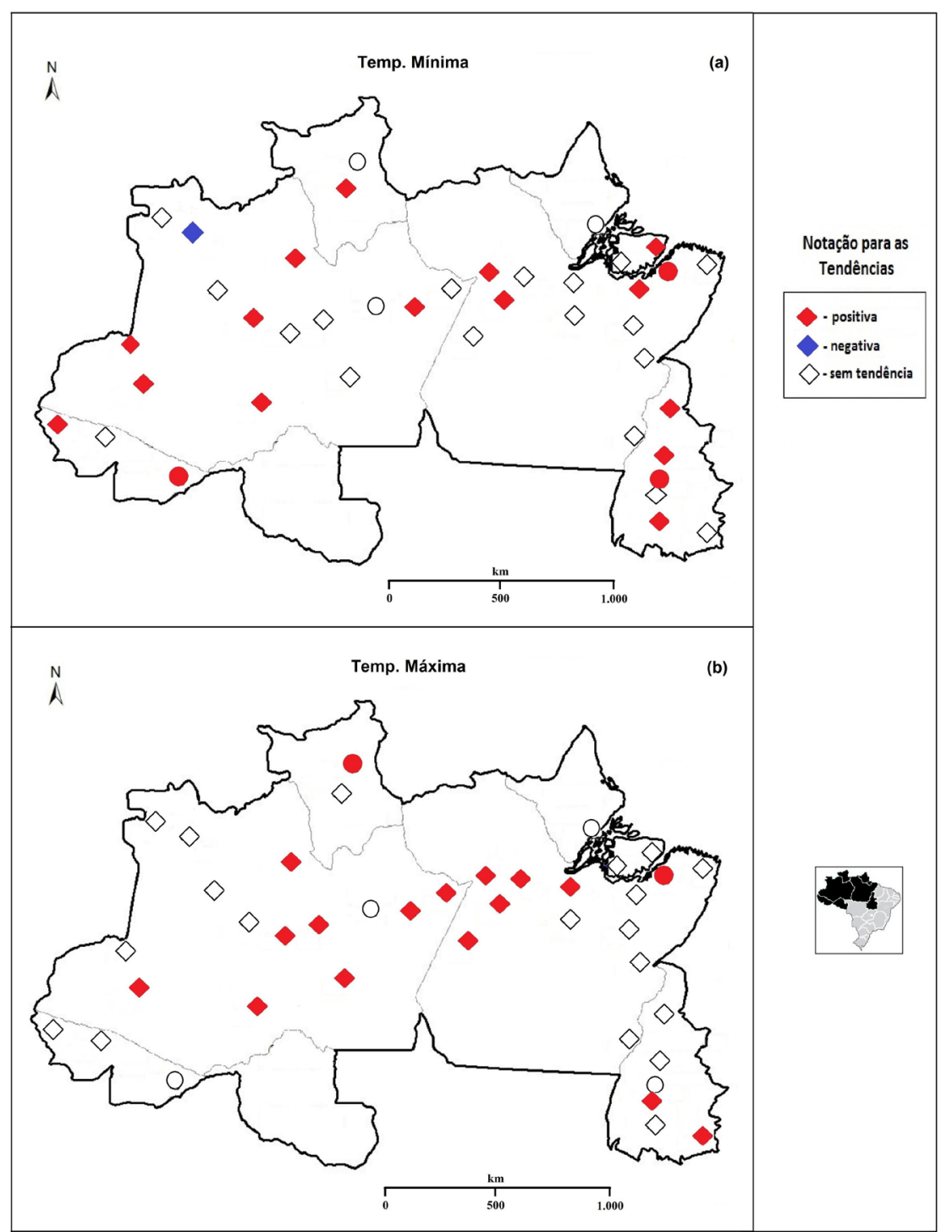

Fonte: Elaborada pelos próprios autores. 
Vinte e três registros de tendências positivas $(+)(+)$, representando $58 \%$ da amostra, foram acusados para a T-méd., desta vez espalhadas por todos estados da referida região brasileira analisada, conforme mostra a Figura 6a. O mapa revela que as ocorrências de tendências nas localidades estudadas possuem certas semelhantes às inferidas para a variável $T$-máx., indicando que provavelmente os cálculos dessas temperaturas tenham sido influenciados pelas medidas feitas na $T$-máx., pois inclui-se ainda o fato de nenhuma tendência negativa ter sido registrada em ambos casos, quando se aplicam os testes estatísticos não paramétricos para essas duas variáveis climáticas.

No tocante à distribuição de tendências para a Prec., mostrado no mapa da Figura 6b, verifica-se que o número de localidades que não apresentaram ocorrências de tendências (35) foi maior que para aquelas que registraram índices positivos (3) ou negativos (2). Neste sentido, os municípios de Barcelos, e Iauaretê com nível de significância entre 5\% e 10\%. Em contra partida, as cidades de Caracaraí, Fonte Boa e Parintins acusaram tendências de aumento de chuvas com significância $(+)(+)$, enquanto que Monte Alegre registrou aumento pluviométrico com tendência $(+)$. Destaca-se ainda que para todas as três localidades do estado do Acre, assim como as capitais dos estados e daquelas cidades nas proximidades da foz dos rios Amazonas e Tocantins, não foram registradas tendências significativas para esta variável climática.

Figura 6 - Mapas das distribuições de tendências climáticas para: (a) T-Méd. e (b) Prec. usando as mesmas indicações representativas da figura anterior

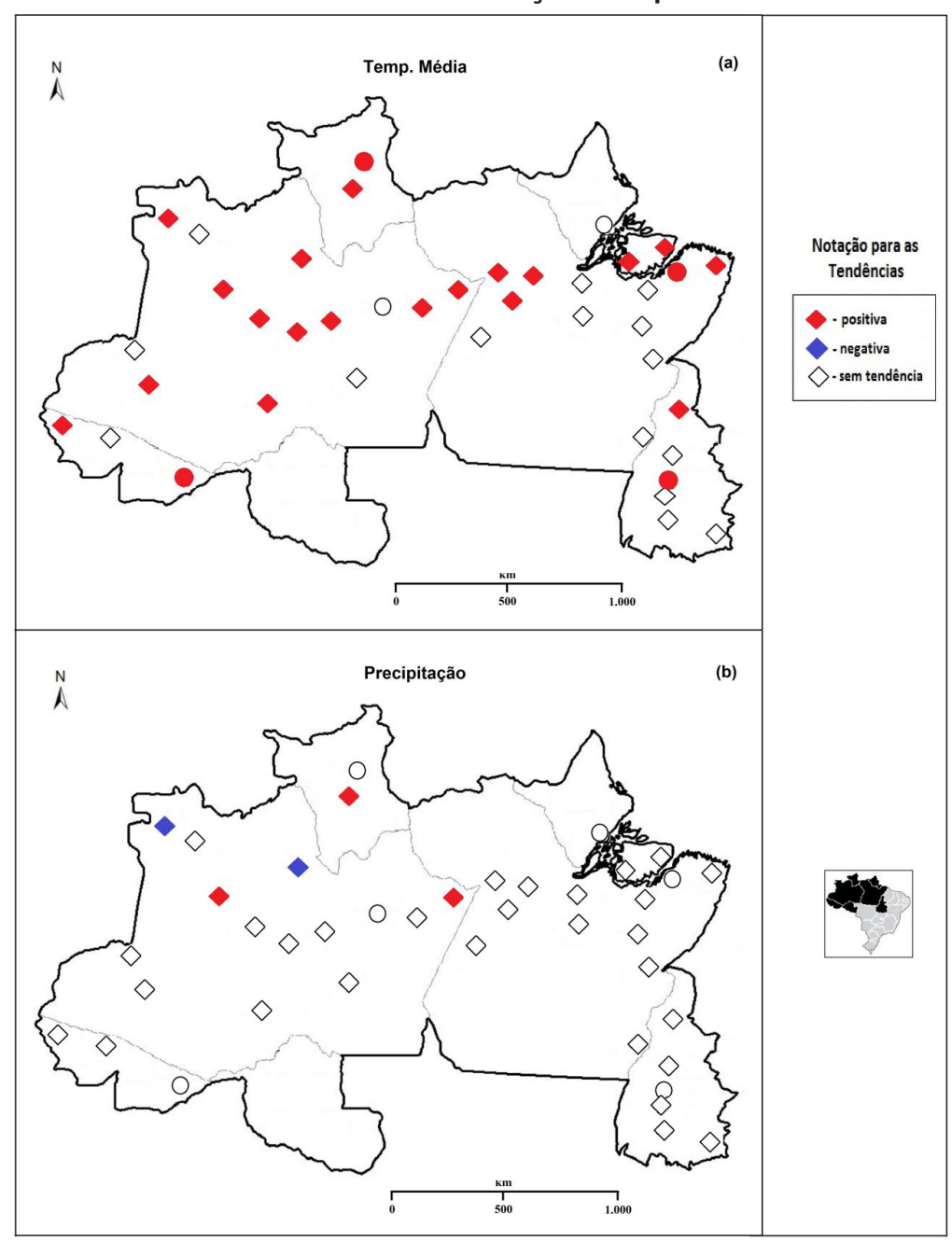

Fonte: Elaborada pelos próprios autores. 
Considerando-se as 40 localidades analisadas neste levantamento com as quatro variáveis climáticas, por meio de uma simples conferência na última coluna da Tabela 2 é possível destacar que: 14 séries temporais (8,75\% da amostra) acusaram tendências antes da década 90, sendo 11 com tendência positiva e 3 com negativa. Um total de 41 séries $(25,63 \%)$ registraram tendências entre as décadas de 90 e início do século XX, com 38 casos de aumento e 3 de diminuição. Após o ano 2000, foram identificadas 19 séries temporais (11,88\%) que evidenciaram tendências, com 18 casos de aumento e apenas um caso de diminuição.

\section{Conclusões}

O presente trabalho teve o intuito de mostrar uma proposta de aplicação de alguns métodos estatísticos que possibilitam realizar uma verificação das ocorrências de tendências em séries temporais de medidas climatológicas coletadas pela rede de estações meteorológicas do INMET espalhadas por toda a região norte do Brasil. Os resultados conquistados permitem afirmar que:

1. As análises tabulares e gráficas das estatísticas aplicadas apresentam concordância entre seus resultados, indicando que os testes paramétrico e não paramétrico podem ser empregados nas análises de tendências em séries temporais.

2. Considerando as quatro variáveis climáticas abordadas, das 160 séries possíveis de serem analisadas, 86 (o que corresponde a 53,75 \%) não indicaram quaisquer indícios de tendências significativas.

3. Das 74 tendências confirmadas (46,25\% de toda amostra tratada), 67 locais identificados $(41,87 \%$ da amostra) acusaram tendências positivas, enquanto que em apenas sete locais $(4,38$ $\%)$ houve a confirmação de tendência negativa.

4. De todas as tendências inferidas, 41 ocorrências foram registradas na última década do século XX, ou seja, em 25,63\% de todos os eventos inferidos.

Os resultados aqui apresentados alertam para o cuidado que se deve ter ao apontar as possíveis causas de mudanças significativas nas séries climáticas, tendo em vista a complexidade em associar essas alterações com as variações naturais do clima e as influências antropogênicas. Apesar de todas as incertezas associadas às mudanças climáticas e, consequentemente, aos impactos dessas possíveis alterações nas séries climáticas, como apresentado e discutido neste trabalho, estudos nessa linha são relevantes e oportunos para auxiliar gestores de recursos hídricos no cenário atual sobre o comportamento do meio ambiente de uma determinada região.

\section{Agradecimentos}

Ao INMET - Instituto Nacional de Meteorologia - pela disponibilização dos dados utilizados. 


\section{Referências}

ANA-1 - Agência Nacional de Águas. Conjuntura dos Recursos Hídricos no Brasil Informe 2012. Disponível em: <http://www.2.ana.gov.br>. Acesso em: 01 abr. 2016.

ANA-2 - Agência Nacional de Águas. Regiões Hidrográficas Brasileiras - Região Hidrográfica Amazônica. Disponível em: <http://www3.ana.gov.br/portal/ANA/todosos-documentos-do-portal/documentos-spr/mapas-regioes-hidrograficas/amazonica-parasite-ana-a0.pdf>. Acesso em: 07 mai. 2016.

BACK, A. J. Aplicação de análise estatística para identificação de tendências climáticas. Pesquisa Agropecuária Brasileira, Brasília, v.36, p.717-726, 2001.

CHIBANA, E. Y.; FLUMIGNAN, D.; MOTA, R. G.; VIEIRA, A. S.; FARIA, R. T. Estimativa de falhas em dados meteorológicos. In: V CONGRESSO BRASILEIRO DE AGROINFORMÁTICA. Londrina, 2005 Anais... Londrina Disponível em: <http:// www.sbiagro.org.br/pdf/v_congresso/Trabalho41.pdf>. Acesso em: 14 abr. 2016.

GROPPO,J.D.;MILDE,L.C.E.; GUAMERO,M.E.;MORAES,J.M.MARTINELLI, L.A. Análise de séries temporais de vazão e precipitação na bacia do rio Piracicaba. Revista Ciência \& Tecnologia, Campinas, v.8, p.109-117, 2001.

INMET - Instituto Nacional de Meteorologia. Banco de Dados para Pesquisa e Ensino - BDMEP. Disponível em: <http://www.inmet.gov.br>. Acesso em: 06 set. 2015.

IPCC - Intergovernmental Panel on Climate Change. Climate Change: The Physical Science Basis. Contribution of Working Group I to the Fifth Assessment Report of the Intergovernmental Panel on Climate Change. Cambridge University Press: Cambridge, United Kingdom and New York, NY, USA, 2013.

KARL,T.R.; DIAZ,H.F.; KUKLA, G. Urbanization: its detection and effect in the United States climate record. Journal of Climate, Boston, v.1: p.1099-1123, 1988.

KENDALL, M. G. Rank correlation methods. London: Charles Griffin, 1975.

KHALIQ,M.N.; OUARDA,T.B.M.J.; GACHON,P.; SUSHAMA, L.; ST-HILAIRE, A. Identification of hydrological trends in the presence of serial and cross correlations: A review of selected methods and their application to annual flow regimes of Canadian rivers. Journal of Hydrology, Amsterdam, v.368, p.117-130, 2009.

MANN, H. B. Nonparametric tests against trend. Econometrica, New York, v.13, p.245259, 1945. 
MARENGO, J. A.; NOBRE, C. A; BETTS, R. A; COX, P. M; SAMPAIO, G; SALAZAR, L. 2009. Global warming and climate change in Amazonia. In: keller M. et al., (Ed.) Amazonia and Global Change. Washington DC: American Geophysical Union, v.186, p.262-273, 2009.

MORAES, J. M.; PELLEGRINO, G.; BALLESTER, M. V.; MARTINELLI, L. A.; VICTORIA, R. L. Estudo preliminar da evolução temporal dos componentes do ciclo hidrológico da bacia do Rio Piracicaba. In: Simpósio Brasileiro de Recursos Hídricos - 11; Simpósio de Hidráulica e Recursos Hídricos dos Países de Língua Oficial Portuguesa - 2; 1995. Anais... Associação Brasileira de Recursos Hídricos, Recife, Pernambuco, p.27-32.

MORTATTI, J.; BORTOLETTO JR, M. J.; MILDE, L. C. E.; PROBST, J. L. Hidrologia dos rios Tietê e Piracicaba: séries temporais de vazão e hidrogramas de cheia. Revista Ciência \& Tecnologia, Campinas, v.12, n.23, p.55-67, 2004.

NAGHETTINI, M. C.; PINTO, E.J.A. Hidrologia Estatística, Belo Horizonte: Serviço Geológico do Brasil (C-PRM), 2007.

PBMC - Painel Brasileiro de Mudanças Climáticas. Sumário Executivo: Base Científica das Mudanças Climáticas. Contribuição do Grupo de Trabalho 1 ao Primeiro Relatório de Avaliação Nacional do Painel Brasileiro de Mudanças Climáticas. (2013). Disponível em: <http://www.pbmc.coppe.ufrj.br/documentos/MCTI_PBMC_Sumario\%20 Executivo\%204_Finalizado.pdf $>$. Acesso em: 07 mai. 2016.

PETTITT, A. N. A non-parametric approach to the change-point problem. Applied Statistics, Pittsburgh, v.28, p.126-135, 1979.

PICKERING, N. B.; HANSEN, J. W.; JONES, J. W.; WELLS, C. M.; CHAN, V. K.; GODWIN, D. C. Weather Man: a utility for managing and generating daily weather data. Agronomy Journal, Madison, v.86, p.332-337, 1994.

SANSIGOLO, C. A.; KAYANO, M. T. Trends of seasonal maximum and minimum temperatures and precipitation in Southern Brazil for the 1913-2006 period. Theoretical and Applied Climatology, Vienna, v.101, p.209-216, 2010.

THOM,H. C. S. Some methods of climatological analysis. Geneve: World Meteorological Organization, WMO. Technical Note 81, v.199. 54p., 1996.

TRENBERTH, K. E.; JONES, P. D.; AMBENJE, P.; BOJARIU, R.; EASTERLING, D.; KLEIN O. Observations: surface and atmospheric climate change. In: Solomon, S.; Qin, D.; Manning, M.; Chen, Z.; Marquis, M.; Averyt, K.B. (eds.) Climate change 2007: 
the physical science basis. Contribution of Working Group I to the Fourth Assessment Report of the Intergovernmental Panel on Climate Change. Cambridge University Press, Cambridge, p.237-336, 2007.

YU, P.; YANG, T. C.; KUO, C. C. Evaluating long-term trends in annual and seasonal precipitation in Taiwan. Water Resources Management, Heidelberg, v.20, p.1007-1023, 2006.

YUE, S.; PILON, P.J.; PHINNEY, B.; CAVADIAS, G. The influence of autocorrelation on the ability to detect trend in hydrological series. Hydrogical Processes, Ontario, v.16, n.16, p.1807-1829, 2002.

ZHENMEI, M.; SHAOZHONG, K.; LU, Z.; LING, T.; XIAOLING, S. Analysis of impacts of climate variability and human activity on streamflow for a river basin in arid region of northwest China. Journal of Hydrology, Minnesota, v.352, p.239-249, 2008. 